\title{
Im Bann der bösen Blume
}

«Minimal art» ist die Kunst, mit sparsamsten Mitteln viel Bedeutung zu schaffen. Auch wenn sie im kunsthistorischen Sinn natürlich nicht in diese Kategorie fallen, werden die Arbeiten von Anna, die die SÄZ seit «Menschengedenken» bereichern, diesem Anspruch gerecht. Ein Blick auf die gegenüberliegende Seite belegt diese Aussage einmal mehr.

Nun kann man bekanntlich alles übertreiben. Und - es sei hier freimütig gestanden - genau dieses Eindrucks konnte ich mich beim ersten Durchblättern von Annas kürzlich erschienenem neuen Buch* nicht erwehren. Das Geständnis fällt insofern leicht, als das erste Urteil in diesem Fall nicht dem finalen entspricht, ansonsten sich der Schreibende einer Vorstellung dieses Werks wohlweislich enthalten oder diese Aufgabe mehr oder weniger elegant delegiert hätte.

Doch der Reihe nach. «Böse Blume» nennt sich das Buch - ein wunderbar poetischer Titel, der einerseits ein weites assoziatives Feld öffnet,

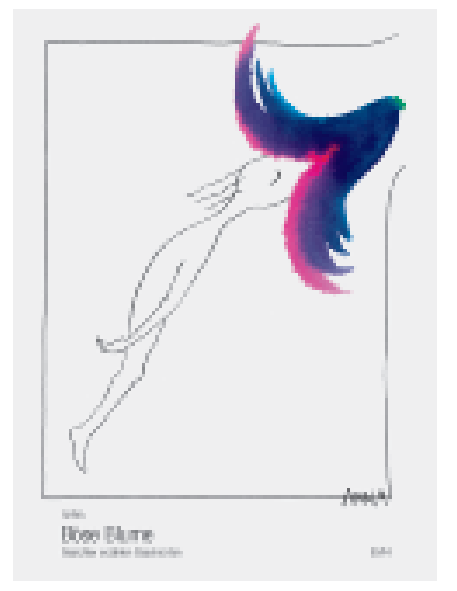

andererseits den gewählten Gegenstand in der Unschärfe seiner Metaphorik trefflich und in gewissem Sinn durchaus präzis charakterisiert. Es geht um Drogen und Sucht, vor allem aber um Menschen und «Geschichten, die mit der Sucht nach Drogen zu tun haben», wie es Anna in der Einleitung selbst ausdrückt. Die Blume ist von magischer Anziehungskraft, doch ihrer Schönheit und ihrem Duft verfällt hoffnungslos, wer ihr zu nahe kommt. Papaver somniferum, der Schlafmohn, kann als Archetyp der bösen Blume gesehen werden. Aus seinem milchigen Saft wird das Opium, Sinnbild der Droge schlechthin, gewonnen.
Das Titelbild zeigt sie denn auch, die «böse Blume», in deren weit geöffneten, in überwiegend dunklen Violett-, Blau- und Grüntönen schimmernden Blütenkelch ein entrücktes menschliches Wesen seinen Kopf eintaucht. Die schlaff-entspannte Haltung erinnert frappierend an einen Skispringer im Flug, ein Eindruck, der durch die wehenden Haare verstärkt wird. Es ist ein Blindflug, wie die geschlossenen Augen zeigen. Das Schweben eines Träumenden, der der Schwere des Erdendaseins entflohen ist.

Es ist beeindruckend, wie Anna in diesem Fall das eingangs skizzierte Prinzip der «minimal art» auf die Spitze treibt. Sparsamer geht's nimmer. Obschon die Mundpartie durch die Blüten verdeckt wird, ist man sich sicher, dass der Schwebende selig lächelt - Körperhaltung und vor allem der Strich des geschlossenen Augenlids schliessen andere Vorstellungen nahezu aus. Diese reduktionistische Arbeitsweise ist auch kennzeichnend für die 40 Porträts im Innern des Buchs. Sie verleiht den Bildern eine Klarheit und Stärke, die man mit dem Begriff «wesentlich» charakterisieren könnte. Klarheit und Stärke können schwierig auszuhalten sein. Ob es daran liegt, dass einige der Porträtierten ihre gezeichneten Gesichter mit Hilfe des Kopierapparats so lange nachbearbeiteten, bis die resultierenden Zerrbilder ihrer Selbstwahrnehmung entsprachen? Auf ein seliges Lächeln stösst man dabei übrigens nicht.

Anna vertraut weitestgehend auf die Kraft ihrer Zeichnungen, sie liefert den Betrachtern lediglich ein Minimum an Begleittext. Dies mag auf den ersten Blick als Schwäche des Buchs erscheinen: Man fühlt sich mit den Bildern etwas allein gelassen und «hilflos». Nimmt man die Herausforderung an und lässt sich auf die Gesichter ein, erweist sich dieses Konzept indes als stimmig. «Süffige» Begleittexte mit Details zu Biographie und Suchtanamnese würden den $\mathrm{Zu}$ gang zu den Menschen und ihren Geschichten zwar erleichtern, den Blick auf das Wesentliche aber möglicherweise verstellen und einen oberflächlich-voyeuristischen Konsum des Buches begünstigen. Und das wäre bei dieser Thematik wohl die «schlimmstmögliche Wendung», um mit einem Wort von Dürrenmatt zu schliessen.

Bruno Kesseli 